\title{
Latent Palm Print's Ridge Density; A Study on Gender Perception on The Population of Western Uttar Pradesh
}

\author{
Amit Chauhan \\ Amity Institute of Forensic Sciences, Amity University, Noida Uttar Pradesh, India \\ Corresponding Author: Amit Chauhan, Amity Institute of Forensic Sciences, Amity University, Noida Uttar \\ Pradesh, India. Tel: +91-9540067484, E-mail: amit_chauhan777@yahoo.in
}

Received Date: 18 December, 2018; Accepted Date: 11 January, 2019; Published Date: 21 January, 2019

\begin{abstract}
Palm prints and Fingerprints have been utilized a mean of identification by numerous scientists because of its nature; perpetual, unique and ubiquitous. In addition of being highly utilized for identification and substantiation of suspects, now a day, the researchers are focusing on palmar surface. Palmar surface covers the larger surface of hand and have higher chances to be implemented over the contacted surface area. The intensified palm prints play a vital role of identification and even provide the gender perception which is considered a crucial facet. This study was focused on determination of gender in which 400 samples (including 200 males and 200 female) were collected from an age group of 15-50 years from the population of western Uttar Pradesh. The ridge densities of intensified palm prints were studied by following an international procedure $\left(25 \mathrm{~mm}^{2}\right)$. As a denouement, the procured mean ridge density, if $\leq 12$ ridges $/ 25 \mathrm{~mm}^{2}$ or less then is likely to be male origin, and $14 \geq$ ridges $/ 25 \mathrm{~mm}^{2}$ or more then that is likely to be from female origin. The obtained results of this study can be helpful to minimize the number of suspects list and nab them behind the bars.
\end{abstract}

\section{Keywords}

Gender Determination; Identification; Latent Palmprints; Ridge Density; Suspects

\section{Introduction}

Almost in every instance of crime investigation, identification of suspect relay on the various forms of evidences recovered from crime scene [1]. These evidences may be observed in physical, chemical or biological forms which provide the link between the suspect and victim involved in crime [2]. In 65\% of cases, the palm prints and fingerprints are recovered in various forms i.e. latent form, patent, plastic are observed $[3,4]$. Due to the nature of ubiquitous, perpetual and exclusive, palm prints have their own significance in an investigation [5]. It has been considered that no two fingerprints or palm prints are similar in this universe and possibility of being is about $1.5 \times 10^{19}$. It must be remembered that while writing or preparing the works of art, etc. one cannot help touching or holding the writing surface [6]. A part of the palm resting on the writing surface to give support and facilitating the movement of the hand. Since the Palm/ fingers have raised lines and furrows having sweat pores which keeps the ridges moist $[7,8]$. Hence as it touches the writing surface or objects, it is expected to leave their impressions of hypothenar area; the lower part of palmar area of palm in latent form on the writing surface or papers [9].

Since, sweat is a color less fluid, Therefore the prints left behind are not visible to the naked eyes. These types of prints are required careful intensification by using an appropriate method. Since the contact of palm prints takes place in a partial form (only a portion), Hence, only a few of the ridges are recovered $[10,11]$. The identification can be established by analyzing the individual features between the disputed objects and exemplar. But if, the gender could be identified from the ridge density of the latent palm prints, it will be a milestone in the field of investigation to minimizing the number of suspects [12]. This study was carried out to determine the gender from the ridge density of hypothenar area of palm print by following the international standard procedure of $25 \mathrm{~mm}^{2}$. As a denouement of this work, it was observed that the females tend to have higher number of ridge density in comparison of males [13]. The findings of this study suggest that the ridge density of hypothenar area of palm prints might be helpful for inferring the suspects of unknown origin [14]. However, the gender perception from ridge density may vary because of topological area, health of an individual, age, disease and temperature etc. We are looking to make a further comparative study by evaluating the samples from different topological areas and to check their significant level for an investigation. 
Citation: Chauhan A (2019) Latent Plam Print's Ridge Density; A study on Gender Perception on The Population of Western Uttar Pradesh. J Forensic Sci Digit Investig 2019: 46-49.

\section{Methodology}

For this present study, all the 400 samples including (200 male and 200 female) from age group of 18-50 years were selected from the population of Western Uttar Pradesh, North part of India. All the subjects for sampling were selected randomly and the consent was taken earlier. Samples were collected in January 2018 at approximate temperature $3-15^{\circ} \mathrm{C}$, All the individuals were asked to write something/ to put signature on a white paper A-4 size sheet paper. According to the mutual exchange principle, the latent palm prints or a part of hypothenar area was transferred on the white sheet. All the samples were treated by traditional and easily available battery of powder (black powder) and the intensified prints were used for further analysis.

\section{Material \& Methods}

For sample collection, the primary information about the subject whether they can put their sign on papers was confirmed. All the subjects were asked to sit at ease and then to write a sentence/ or to follow the standard letter/ to put the signature on a white A-4 size sheet with the help of blue ball point pen. During the sampling process, all the individuals were at calm and congenital

atmosphere. During the follow up of the procedure, it was expected that the author/individual will leave the latent palm impression of part their off on the surface of writing surface. By carefully handling, all the samples were kept at room temperature for 7-10 hours and then intensified. After the successful intensification, all the prints were preserved with the help of a $48 \mathrm{~mm}$ diameter cello tape. Intensified palm prints or part their off were clear and were having enough information about the minutiae details of an individual.

The ridge counting was done by following standard procedure $\left(25 \mathrm{~mm}^{2}\right)$ and from corner to corner of the print. The intensified palm prints were photographed by using by Oppo A5 smartphone of 16 megapixels camera. For the analysis of samples stereoscope including hand lens of $5 \mathrm{x}$ and $10 \mathrm{x}$ were used (Figure 1 and 2).

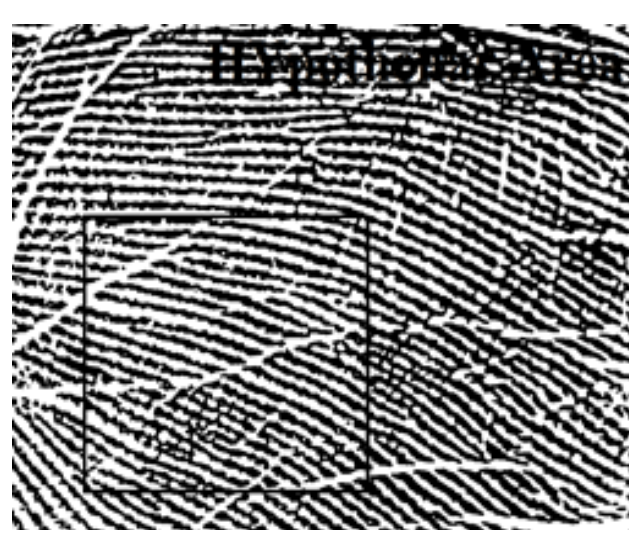

Figure 1: Lower area of palm print (hypothenar area).

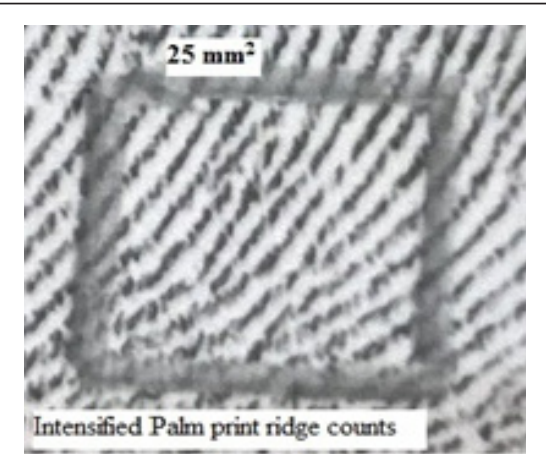

Figure 2:Lower area of palm print (hypothenar area).

For tabulation and calculation, SPSS latest version 17.0 along with MS excel was used. To conclude the individuality of the suspect/individual, two-tailed fashion t-test was embedded in this study. kA hypothesis was set that for gender perception, as per this; $H_{0}$ : there is difference between the two genders based on ridge details of intensified palm prints and while $H_{a}$ : there is no difference between two ganders based on ridge details of intensified palm prints. The likelihood ration (LR) was calculated to obtain the probability inferences of gender, based on ridge density values. The likelihood ratio is based on Baye's theorem $[14,15]$.

LR = Probability of given fingerprint originating from male contributor (C) / Probability of given fingerprint originating from female contributor $\left(\mathrm{C}^{1}\right)$

\section{Result and Discussion}

This study shows that the ride count in hypothenar area of intensified palm prints ridge are lesser in case of male while higher in female. The Male ridge count is higher ( 13 ridges $/ 25 \mathrm{~mm}^{2}$ ) about $47 \%$ while the female has $54 \%$ number of ridges at 15 ridges $/ 25 \mathrm{~mm}^{2}$. No male was observed in the 15 ridges $/ 25 \mathrm{~mm}^{2}$ categories while on other hand, no female was observed in 15 ridges $/ 25 \mathrm{~mm}^{2}$ categories. The detailed information of both of genders ridge count in $25 \mathrm{~mm}^{2}$ are given in Table 1 .

\begin{tabular}{|c|c|c|c|c|}
\hline \multirow{2}{*}{$\begin{array}{c}\text { No. of } \\
\text { Ridg- } \\
\text { es/25mm }\end{array}$} & \multicolumn{2}{|c|}{ Male } & \multicolumn{2}{c|}{ Female } \\
\cline { 2 - 5 } & $\begin{array}{c}\text { No. of } \\
\text { Subjects }\end{array}$ & Percentage & $\begin{array}{c}\text { No. of } \\
\text { Subjects }\end{array}$ & Percentage \\
\hline 11 & 12 & $6 \%$ & - & - \\
\hline 12 & 70 & $35 \%$ & 3 & - \\
\hline 13 & 95 & $47 \%$ & 14 & $1 \%$ \\
\hline 14 & 23 & $11 \%$ & 56 & $7 \%$ \\
\hline 15 & - & - & 109 & $28 \%$ \\
\hline 16 & - & - & 18 & $54 \%$ \\
\hline Total & 200 & & 200 & $9 \%$ \\
\hline
\end{tabular}

Table 1: Number of ridges of an intensified palm print (Hypothenar area) according to gender. 
Citation: Chauhan A (2019) Latent Plam Print's Ridge Density; A study on Gender Perception on The Population of Western Uttar Pradesh. J Forensic Sci Digit Investig 2019: 46-49.

When the statistical analysis was applied was applied in the ridges of both of genders, it was observed that ridge densities ranges from 11 ridges $/ \mathrm{mm}^{2}$ to 14 ridges/ $\mathrm{mm}^{2}$ in male while it ranges from 12 ridges-16ridges $/ 25 \mathrm{~mm}^{2}$ in female. The denouement shows that males have significantly lesser ridge density that female at $\mathrm{p}<0.001$ significance level. Detailed information is given in Table 2.

\begin{tabular}{|c|c|c|}
\hline Statistics derivatives & Male & Female \\
\hline Mean RC & 12.02 & 14.23 \\
\hline SD & 0.79 & 0.085 \\
\hline SE & 0.03 & 0.04 \\
\hline Minimum & 11 & 12 \\
\hline Median & 13 & 14 \\
\hline Maximum & 14 & 16 \\
\hline
\end{tabular}

Table 2: Statistical Analysis of ridge densities of both genders.

The combined mean of both of genders are $13.12 \pm 1.17$ with a minor standard error 0.03 at an obtained t- value 23.74 at significance level $\mathrm{p}<0.001$. The probability density and likelihood ratio of male and female was also calculated by using these values. During this observation, it was noticed that LR is very high for the 11ridges because not even a single female was found in this category and tends to decrease till 13 ridges. It drastically changes and increases from 14 ridges onwards. The details are shown in Table 3. intensified palm prints are highly significant at $\mathrm{p}<0.001$. In some cases, if the female is mostly busy with watery work then tearing of ridges can be encountered and ridge count in a area can be increase (mostly the Palmar area), while the male who works in fields or a laborer; the ridges are found thicker.

During this study, it was also observed that an appropriate method and suitable method play a vital role for the intensification of impressions. A few of conventional application of developing methods can decrease the possibility of less damage. Once the sex of suspect will come to know from the latent palm prints or part then after taking specimen of the suspects; it would be easier for investigator to identify an individual (A methodology of finger mark research).

\section{Conclusion}

Palm prints, which are infallible by the nature because of its uniqueness and in 35\% of cases are encountered at the scene of occurrence [16]. The present study was conducted with an attempt to describe the densities of intensified palm prints ridges and it has been successful for supporting the hypothesis that women tend to have a statistically significant greater ridge density than men. The results have showed that a ridge count of $\leq 12$ ridges $/ 25 \mathrm{~mm}^{2}$ is more likely to be of male origin and that of $\geq 14$ ridges $/ 25 \mathrm{~mm}^{2}$ is likely to be of female origin. It's a milestone to accept evidences in court of law and to establish their relationship with the gender of suspect. Once the sexing could be done, then it's become easier for the investigator nab the suspect.

\begin{tabular}{|c|c|c|c|c|c|c|}
\hline \multirow{2}{*}{ Ridge Count/ 25 mm } & \multicolumn{2}{|c|}{ Probability Density } & \multicolumn{2}{c|}{ Likelihood Ratio } & \multicolumn{2}{c|}{ Favored Odds } \\
\cline { 2 - 7 } & Male & Female & LR & LR & Males & Females \\
\cline { 2 - 7 } & $(\mathbf{C})$ & $\left(\mathbf{C}^{\mathbf{1}}\right)$ & $\mathbf{( C / \mathbf { C } ^ { 1 } )}$ & $\left(\mathbf{C}^{\mathbf{1}} \mathbf{C}\right)$ & & \\
\hline 11 & 0.05 & 0.001 & 500 & 0.002 & 0.99 & 0.01 \\
\hline 12 & 0.23 & 0.003 & 79 & 0.01 & 0.97 & 0.04 \\
\hline 13 & 0.39 & 0.11 & 6.1 & 0.25 & 0.81 & 0.21 \\
\hline 14 & 0.13 & 0.47 & 0.6 & 3 & 0.29 & 0.72 \\
\hline 15 & 0.001 & 0.52 & 0.04 & 28 & 0.07 & 1 \\
\hline 16 & 0.001 & 0.16 & 0.01 & 117 & 0 & 1 \\
\hline
\end{tabular}

Table 3: Probability densities and likelihood ratios obtained from observed ridge count of intensified palm prints.

Numerous studies have been conducted on the ridge density to determine the gender and any kind of genetic inheritance in ridge pattern. This study was conducted to broaden the area of palm prints and its utilization for gender discrimination from the ridge count similar like of fingerprints. The outcome if this study is utterly encouraging which can be helpful tool in the field of forensic investigation and restrict their field of minimizing the list of suspects of a specific gender. It proves that an increased ridge density in female gender rather than male gender because of less coarseness of ridges. This study of gender perception from

\section{References}

1. Shende Sumit, More Sarika, Malini Ajit, Shastikaa N (2013) to study the correlation between stature and palmprints among North Indian and South Indian populations. J forensic Med Sci law 22: 107-111.

2. Kaur Ramanjit, Garg Rakesh K (2011) determination of gender difference from fingerprint ridge density in two North Indian Populations. Problems of Forensic Sci 85: 5-10.

3. Chitra SV, Amarnath A, Smitha SV, Harindranathan Nair MV (2013) Estimation of effective impressions surface area of coachin using satellite images. Res J Recent Sci 2: 241-244. 
Citation: Chauhan A (2019) Latent Plam Print's Ridge Density; A study on Gender Perception on The Population of Western Uttar Pradesh. J Forensic Sci Digit Investig 2019: 46-49.

4. Khadri Sayed Yunus, Goudar ES, Khadri Sayeda Yasmeen (2013) A study of fingerprint pattern and gender distribution of fingerprint in and around Bijapur. Al Ameen J Medical Sci 6: 328-321.

5. Wadhwa Ravi, Kaur Maninder, Singh KVP (2013) Age and gender determination from fingerprint Using RVA and Dct coefficients. IOSR J Eng 3: 05-09.

6. Gornale SS, Geetha CD, Kruthi R (2013) Analysis of fingerprint image for gender classification using spatial and frequency domain analysis. Am int J Res Sci Technol Eng Math13: 46-50.

7. Kaur Ritu, Ghosh Susmita Mazumdar (2012) Fingerprint based gender Identification using frequency domain analysis. Int j adv eng technol 3: 295-299.

8. Amit Chauhan, Jyoti Singh, Ritu Sharma (2015) Determination of sex from the latent palm prints present on documents. Int $\mathrm{J}$ res Eng applied Sci 5: 148-153.

9. Karalik Miroslav, Novotny Vladimir (2013) Epidermal ridge breadth an indicator of age and sex in paleodermoglyphics. Variability and Evolution 11: 5-30.

10. Redomero, Esperanza Gutierrez, Concepcion Alonso, Romero Esther, Galera Vriginia (2008) Variability of fingerprint ridge density in a sample of Spanish Caucasians and its application to sex determination, Forensic Sci int 180: 17-22.

11. McDonald Idu (2013) Science and technology in the 21st century: Phytomedicine in Focus. Res J Recent Sci 2: 1-7.

12. Gungadin Sudesh (2007) Sex determination from fingerprint ridge density. Int J med update 2: 4-7.

13. Eboh Dennis EO (2012) Fingerprint patterns in relation to gender and blood group among students of delta state University, Abraka, Nigeria. J Experimental clinical anatomy 12: 82-86.

14. Agnihotri Anil Kumar, Jowaheer Vandna, Allock Anishta (2012) An analysis of fingerprint ridge density in Indo- Mauritian population and its application to gender determination. Med Sci law 52: 143147.

15. Noushin Kamali Sajjad, Badri Abbasi (2014) Studying the relationship between quality of work life and organizational commitment. Res J Recent Sci 3: 92-99.

16. Amit Chauhan, Jyoti Singh (2014) Identification of an individual from latent palm prints present on documents. Int J Res Sci Innovation 1: 29-35.

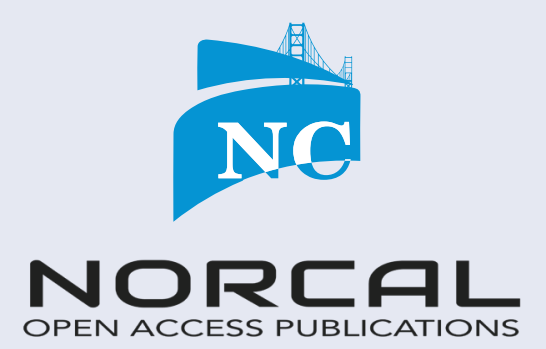

submit your manuscripts at www. norcaloa.com 